\title{
ESTUDOS SOBRE O STATUS ECOLÓGICO DE CRUSTÁCEOS AEGLIDAE (PLEOCYEMATA: ANOMURA) ATRAVÉS DE ANÁLISES ISOTÓPICAS
}

\author{
Denadai, A.C. ${ }^{1,}$; Gonçalves, G.R.L. ${ }^{1}$; Garcia, J.R. ${ }^{1}$; Costa, V.E. ${ }^{2}$ \& Castilho, A.L. ${ }^{1}$ \\ 1 Universidade Estadual Paulista Júlio de Mesquita Filho (UNESP), Campus Botucatu, Instituto de Biociências - \\ Zoologia - NEBECC; ${ }^{2}$ Centro de Isótopos Estáveis Prof. Dr. Carlos Ducatti, Instituto de Biociências - IBB, UNESP. \\ *Autor correspondente: acdenadai@outlook.com
}

\begin{abstract}
Os eglídeos são endêmicos da região Neotropical da América do Sul, restritos ao ambiente de corredeira, baixas temperaturas, altos teores de oxigênio e são considerados protagonistas na dinâmica de nutrientes e fluxo de energia. O objetivo deste estudo foi analisar os níveis de nitrogênio (N) e carbono (C) de Aegla castro e Aeg/a parana capturados em riachos da região sudeste e sul do Brasil. Os espécimes foram obtidos de 2016 a 2017, por coleta passiva, com armadilhas aleatoriamente distribuídas nos riachos. Em seguida, o tecido muscular dos indivíduos foi analisado isotopicamente para $\delta^{13} \mathrm{C}$ e $\delta^{15} \mathrm{~N}$ e testados quanto a prováveis diferenças (ANOVA, Tukey). Diferenças de $\mathrm{C}$ e $\mathrm{N}$ foram encontradas entre as regiões (ANOVA, $\mathrm{df}=6 ; \mathrm{F}=13,06 ; \mathrm{P}=0,00$ ), onde Castro - PR (Aegla castro Schmitti, 1942) foi a região distinta das demais (Tukey, $\mathrm{P}=0,00$ ), com o maior nível de $\mathrm{N}$ e o menor para $\mathrm{C}$, inversamente ao registrado no Canyon Guartelá (Castro-Tibagi, PR), para a mesma espécie. As demais regiões tiveram valores intermediários de ambas as assinaturas isotópicas para A. castro (Itatinga-SP e Mauá da Serra-PR), bem como para Aegla parana Schmitti, 1942 (União da Vitória-PR). O C proporciona a identificação das fontes primárias, pois sua razão isotópica muda pouco entre o consumidor e o recurso. Já o $\mathrm{N}$ propicia a oportunidade de mensuração das posições tróficas dos consumidores, uma vez que sua razão isotópica muda de maneira similar entre os níveis. Os valores de C são favorecidos pelo aporte de serapilheira, detritos vegetais, algas, e alta produção de macrófitas. Já o de $\mathrm{N}$ através de matéria orgânica, Insecta, Mollusca, Platyhelminthes, Porifera, e Crustacea. Valores elevados de $\mathrm{N}$ e baixos para $\mathrm{C}$ quando comparados para a mesma espécie ou espécies congêneres relacionam-se a hábitos alimentares distintos ou devido à interferência antrópica, visto que a disposição de fontes alimentares oriundas de produtores e consumidores primários pode diminuir com alterações do ambiente, alterando o comportamento predatório. Estes resultados indicam uma diversidade de hábitos alimentares, dependentes do que estão disponíveis no ambiente, onde esses anomúros desempenham um papel importante na reciclagem de nutrientes. A atividade humana é outro fator que influencia diretamente estes animais, através de descargas de dejetos e consequente ao aumento da matéria orgânica, elevando o nível de $\mathrm{N}$ dos animais que os consomem, o que pode gerar instabilidade e até mesmo diminuição da população local.
\end{abstract}

Palavras-chave: eglídeos, generalista, isótopos estáveis.

Financiamento: FAPESP № 2016/20177-0. 